\title{
Effect of triiodothyronine on mitochondrial energy coupling in human skeletal muscle
}

\author{
Vincent Lebon, ${ }^{1}$ Sylvie Dufour, ${ }^{1}$ Kitt Falk Petersen, ${ }^{2}$ Jianming Ren, ${ }^{3}$ Beat M. Jucker, ${ }^{2}$ \\ Lori A. Slezak, ${ }^{4}$ Gary W. Cline, ${ }^{2}$ Douglas L. Rothman, ${ }^{5}$ and Gerald I. Shulman ${ }^{1,2,6}$ \\ ${ }^{1}$ Howard Hughes Medical Institute, and \\ ${ }^{2}$ Department of Internal Medicine, Yale University School of Medicine, New Haven, Connecticut, USA \\ ${ }^{3}$ Department of Metabolic Research, Bristol-Myers Squibb Co., Princeton, New Jersey, USA \\ ${ }^{4}$ Department of Surgery, \\ ${ }^{5}$ Department of Diagnostic Radiology, and \\ ${ }^{6}$ Department of Cellular and Molecular Physiology, Yale University School of Medicine, New Haven, Connecticut, USA
}

Address correspondence to: Gerald I. Shulman, Howard Hughes Medical Institute, Yale University School of Medicine, BCMM 254C, 295 Congress Avenue, New Haven, Connecticut 06510, USA.

Phone: (203) 785-5447; Fax: (203) 737-4059; E-mail: gerald.shulman@yale.edu.

Vincent Lebon, Sylvie Dufour, and Kitt Falk Petersen contributed equally to this work.

Received for publication November 13, 2000, and accepted in revised form July 24, 2001.

\begin{abstract}
The mechanism underlying the regulation of basal metabolic rate by thyroid hormone remains unclear. Although it has been suggested that thyroid hormone might uncouple substrate oxidation from ATP synthesis, there are no data from studies on humans to support this hypothesis. To examine this possibility, we used a novel combined ${ }^{13} \mathrm{C} /{ }^{31} \mathrm{P}$ nuclear magnetic resonance (NMR) approach to assess mitochondrial energy coupling in skeletal muscle of seven healthy adults before and after three days of triiodothyronine $\left(\mathrm{T}_{3}\right)$ treatment. Rates of ATP synthesis and tricarboxylic acid (TCA) cycle fluxes were measured by ${ }^{31} \mathrm{P}$ and ${ }^{13} \mathrm{C}$ NMR spectroscopy, respectively, and mitochondrial energy coupling was assessed as the ratio. Muscle TCA cycle flux increased by approximately $70 \%$ following $\mathrm{T}_{3}$ treatment. In contrast, the rate of ATP synthesis remained unchanged. Given the disproportionate increase in TCA cycle flux compared with ATP synthesis, these data suggest that $\mathrm{T}_{3}$ promotes increased thermogenesis in part by promoting mitochondrial energy uncoupling in skeletal muscle.
\end{abstract}

J. Clin. Invest. 108:733-737 (2001). DOI:10.1172/JCI200111775.

\section{Introduction}

The regulation of basal metabolic rate by thyroid hormone has been known since the 18th century (1), but the mechanism by which it occurs remains controversial. Thyroid hormone has been shown to increase energy expenditure by activating $\mathrm{Na}^{+} / \mathrm{K}^{+}$-ATPase, stimulating futile cycling as well as promoting mitochondrial biogenesis (2-6). However, in vitro observations have raised the possibility that thyroid hormone also promotes mitochondrial uncoupling of substrate oxidation from ATP synthesis $(7,8)$. The absence of an identified mechanism that accounts for uncoupling and the inability to assess the degree of mitochondrial coupling in vivo have long hampered investigation into the regulation of this process. Recently, a skeletal muscle-specific uncoupling protein (UCP-3) has been cloned in humans (9). This protein is thought to create a pathway that allows exothermic movement of protons through the inner mitochondrial membrane. A positive correlation between the concentration of thyroid hormone in plasma and UCP-3 mRNA expression in skeletal muscle has been demonstrated in mice, rats, and humans (10-18), raising the possibility that UCP-3 might be involved in regulating energy expenditure and body weight in humans by promoting mitochondrial energy uncoupling.
In order to examine whether thyroid hormone is capable of inducing mitochondrial uncoupling in human skeletal muscle, we developed a combined ${ }^{13} \mathrm{C} /{ }^{31} \mathrm{P}$ nuclear magnetic resonance (NMR) approach to assess mitochondrial energy coupling in vivo. The rate of tricarboxylic acid (TCA) cycle flux was assessed by monitoring the rate of appearance of ${ }^{13} \mathrm{C}$ label into the $\mathrm{C} 4$ and $\mathrm{C} 2$ carbon atoms of muscle glutamate during an intravenous infusion of $\left[2-{ }^{13} \mathrm{C}\right]$ acetate (12). The rate of ATP synthesis was measured using ${ }^{31} \mathrm{P}$ NMR spectroscopy by direct observation of ${ }^{31} \mathrm{P}$ magnetization transfer between inorganic phosphate $\left(\mathrm{P}_{\mathrm{i}}\right)$ and the $\gamma$ phosphate resonance of ATP ( $\gamma$ ATP); mitochondrial energy coupling was determined by the ratio of ATP synthesis to TCA cycle oxidation. To assess the effect of thyroid hormone on mitochondrial energy coupling, these measurements were performed in healthy volunteers before and after three days of treatment with triiodothyronine $\left(T_{3}\right)$ to induce a state of mild hyperthyroidism.

\section{Methods}

Protocol. NMR studies were performed on seven healthy volunteers (three men and four women, aged $25 \pm 2$ ) before (basal) and after three days of $\mathrm{T}_{3}$ treatment $(100$ $\mu \mathrm{g}$ orally every 12 hours). Whole-body oxygen consumption was measured using a DeltaTrac II indirect 


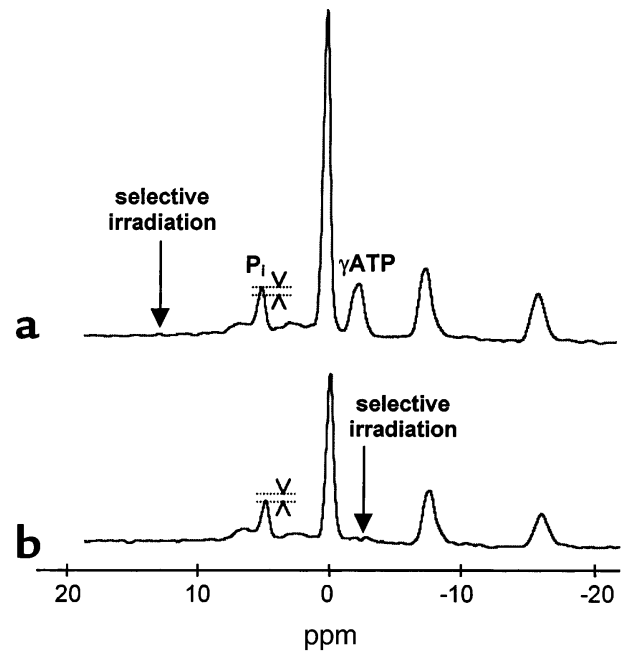

Figure 1

Principle of ATP synthesis rate measurement by ${ }^{31} \mathrm{P}$ NMR spectroscopy. (a) Control spectrum in one volunteer: the saturation pulse is applied symmetrically to the $\gamma$ ATP Larmor frequency. (b) Spectrum with $\gamma$ ATP saturation acquired in the same volunteer $(N S=128)$. Subtraction of spectrum (b) from (a) gives the fraction of $\mathrm{P}_{\mathrm{i}}$ involved in the synthesis of ATP, as shown on the $P_{i}$ peak. ppm, parts per million.

calorimeter (SensorMedics Corp., Yorba Linda, California, USA) before and after $\mathrm{T}_{3}$ treatment. All measurements were performed at rest following a 12-hour overnight fast at thermoneutrality $\left(22-23^{\circ} \mathrm{C}\right)$.

Informed written consent was obtained from all subjects after the aims and potential risks of the study were explained to them. The protocol was approved by the Yale University School of Medicine Human Investigation Committee.

NMR spectroscopy. NMR studies were performed on a 2.1 $\mathrm{T}$ whole-body (1- $\mathrm{m}$ bore) magnet connected to a modified AVANCE spectrometer (Bruker, Billerica, Massachusetts, USA). Subjects remained supine in the magnet with the main body of the right calf muscles lying on top of a home-built radio-frequency NMR probe.

${ }^{31} \mathrm{P} N M R$ measurement of ATP flux. ${ }^{31} \mathrm{P}$ spectroscopy was performed at $36.31 \mathrm{MHz}$, using a flat concentric probe made of a $9-\mathrm{cm}$ (diameter) inner coil (for ${ }^{31} \mathrm{P}$ ) and a $13-\mathrm{cm}$ outer coil tuned to proton frequency for scout imaging and shimming.

Unidirectional rates of ATP synthesis were measured using the saturation transfer experiment applied to the exchange between $P_{i}$ and ATP. The steady-state $P_{i}$ magnetization $M_{\mathrm{z}}$ was measured in the presence of selective irradiation of the $\gamma \mathrm{ATP}$, and compared with the equilibrium $P_{i}$ magnetization $M_{0}$ in a control spectrum (without irradiation of $\gamma$ ATP), as shown in Figure 1.

The fractional reduction of $P_{i}$ magnetization upon $\gamma$ ATP saturation $\left(M_{0}-M_{z}\right) / M_{0}$ was measured from our spectra and was used in the calculation of the pseudofirst-order rate constant according to the equation of Forsen and Hoffman: $k_{1}=\left[\left(M_{0}-M_{z}\right) / M_{0}\right]\left(1 / T 1^{*}\right)$, where $T 1 *$ is the spin-lattice relaxation time for the phosphorus nucleus of $P_{i}$ when ATP is saturated.
$T 1^{*}$ was then measured using a modified version of the inversion-recovery experiment $\left(180^{\circ}-\tau-90^{\circ}\right.$-acq-ID) in the presence of steady-state saturation of $\gamma$ ATP during the total interpulse delay (ID) of 4 seconds and during the variable delay $(\tau) . T 1 *$ was evaluated using a nonlinear least-squares fitting method. Unidirectional flux of ATP synthesis was then calculated by multiplying the constant $k_{1}$ by the $\mathrm{P}_{\mathrm{i}}$ concentration. The $\mathrm{P}_{\mathrm{i}}$ concentration was measured from the control spectrum, assuming a constant ATP concentration of $5.5 \mathrm{mmol} / \mathrm{kg}$ in muscle (19).

Total acquisition time for ${ }^{31} \mathrm{P}$ spectra was about 120 minutes. After completion of ${ }^{31} \mathrm{P}$ measurements, the volunteer was removed from the magnet for a 10minute break. The NMR radio-frequency probe was changed, and the volunteer was repositioned for measurement of the TCA cycle rate.

${ }^{13} \mathrm{C} N M R$ measurement of TCA cycle flux. For ${ }^{13} \mathrm{C}$ spectroscopy, the probe consisted of one ${ }^{13} \mathrm{C}$ circular coil and two ${ }^{1} \mathrm{H}$ quadrature coils for ${ }^{1} \mathrm{H}$ acquisitions and decoupling. After tuning, shimming with the FASTERMAP procedure (20), and acquiring scout images, ${ }^{13} \mathrm{C}$ NMR spectra were acquired for 20 minutes before and during a 120 -minute $\left[2-{ }^{-13} \mathrm{C}\right]$ acetate infusion $(350 \mathrm{mmol} / \mathrm{l}$ sodium salt, 99\% ${ }^{13} \mathrm{C}$ enriched; Isotec Inc., Miamisburg, Ohio, USA) at an infusion rate of $2.9 \mathrm{mg} / \mathrm{kg} / \mathrm{min}$.

${ }^{13} \mathrm{C}$ NMR spectra were acquired using either an imageselected in vivo spectroscopy (ISIS) sequence ( $\mathrm{TR}=2.3 \mathrm{sec}-$
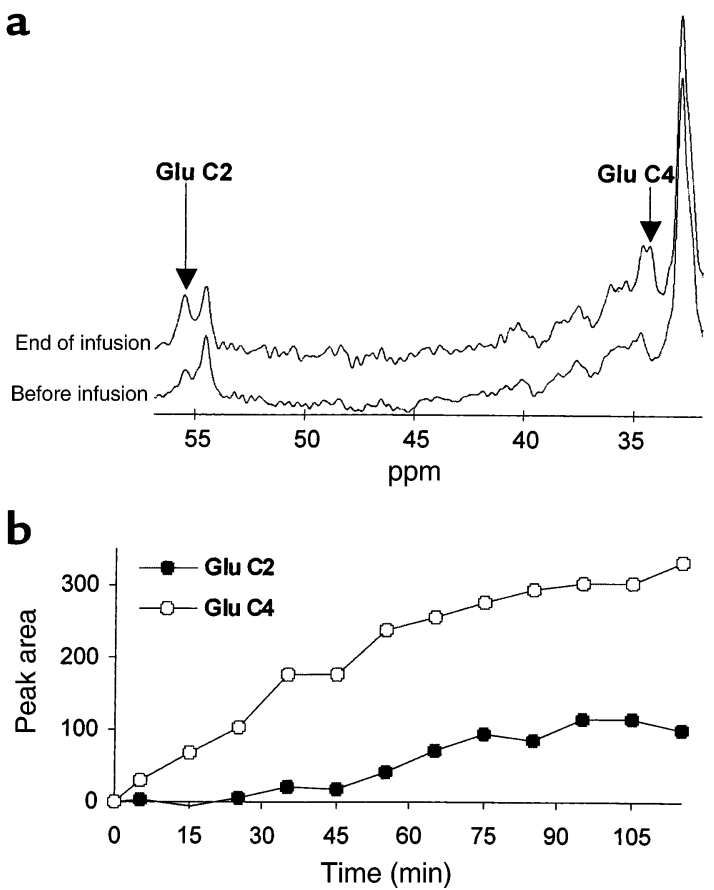

Figure 2

${ }^{13} \mathrm{C}$ NMR data. (a) ${ }^{13} \mathrm{C}$ spectra acquired in a volunteer before and at the end of the $\left[2-{ }^{13} \mathrm{C}\right]$ acetate infusion. (b) Time course of glutamate C4 and glutamate C2 peak areas during the same experiment. Glutamate $\mathrm{C} 4$ appears soon after the beginning of the $\left[2-{ }^{13} \mathrm{C}\right]$ acetate infusion. The increase in glutamate $\mathrm{C} 2$ is delayed in comparison to that of glutamate $C 4$, reflecting the extra turn of the TCA cycle required to randomize the ${ }^{13} \mathrm{C}$-labeled carbon into this position. 


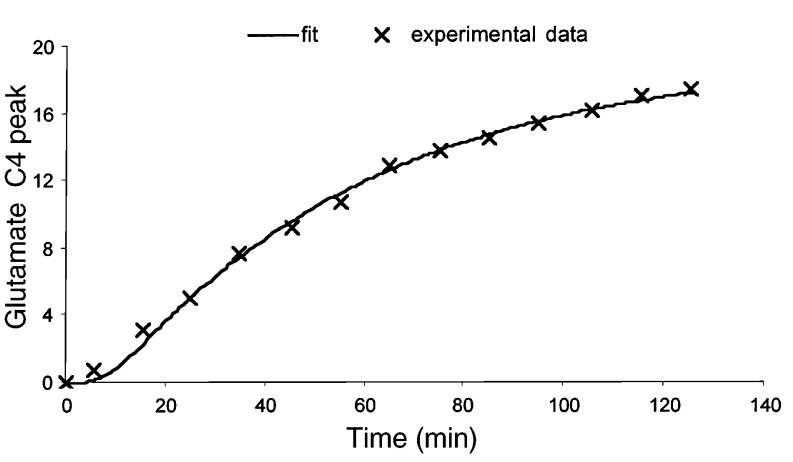

Figure 3

Typical model fit of the ${ }^{13} \mathrm{C}$ NMR data of glutamate $\mathrm{C} 4$ in skeletal muscle $\left(R^{2}=0.93\right)$.

onds), or a nonlocalized sequence ( $\mathrm{TR}=1.4$ seconds) with suppression of the 34.4 parts per million ( $\mathrm{ppm}$ ) lipid signal after inversion by an adiabatic pulse. Temporal resolution was 10 minutes. After Fourier transformation and baseline subtraction, glutamate $\mathrm{C} 2$ peaks were integrated between 55.3 and $55.8 \mathrm{ppm}$, and glutamate $\mathrm{C} 4$ peaks were integrated between 33.6 and $35.0 \mathrm{ppm}$ (Figure 2).

Fractional enrichments and plasma acetate were measured from blood samples collected at 10-minute intervals and analyzed on a Hewlett-Packard 5890 gas chromatograph (HP-1 capillary column, $12 \mathrm{~m} \times 0.2$ $\mathrm{mm} \times 0.33 \mathrm{~mm}$ film thickness) interfaced to a HewlettPackard 5971A mass selective detector operating in the electron impact ionization mode (12).

TCA cycle flux was assessed by monitoring the incorporation of ${ }^{13} \mathrm{C}$ into glutamate from $\left[2-{ }^{13} \mathrm{C}\right]$ acetate and modeling the data using Cwave software $(21,22)$. An intracellular concentration of glutamate in skeletal muscle of $2.41 \pm 0.28 \mathrm{mmol} / \mathrm{l}$ (as measured in the muscle biopsies described below) was used in the model. The model describes the increase in glutamate $\mathrm{C} 4$ labeling resulting from $\left[2-{ }^{13} \mathrm{C}\right]$ acetate conversion into $\left[2-{ }^{13} \mathrm{C}\right]$ acetyl CoA, which in turn condenses with oxaloacetate to produce $\left[4-{ }^{-13} \mathrm{C}\right]$ citrate; this in turn labels $\alpha$-ketoglutarate $\mathrm{C} 4$, which then equilibrates with glutamate $\mathrm{C} 4$. Following the second turn of the cycle, $\mathrm{C} 2$ and C3 of glutamate become labeled. Nonlinear least squares fit of glutamate $\mathrm{C} 4$ and $\mathrm{C} 2$ yielded an estimate of TCA cycle flux. A typical fit of the C4 glutamate data is shown in Figure 3. It is important to note that the TCA cycle flux calculated from our mathematical model is independent of both the amount of acetate incorpo- rated into the TCA cycle (flux through acetyl CoA synthetase) and the substrate source (glucose, fatty acids, or acetate). This approach is similar to the methodology developed and validated by Chatham et al. in the perfused heart, which found a 1:1 relationship between ${ }^{13} \mathrm{C}$ NMR-determined rates of oxygen consumption and measured rates of oxygen consumption (23).

Muscle biopsies. Muscle tissue (50-100 mg) was obtained from the vastus lateralis muscles of three additional subjects by a punch biopsy procedure using a 5-mm Bergstrom biopsy needle (Life Medical Equipment, Miami, Florida, USA); this was done before and after $\mathrm{T}_{3}$ treatment in order to determine muscle glutamate concentration for the TCA cycle flux calculations. The muscle tissue was quickly blotted on filter paper and immediately frozen in liquid nitrogen. The time from obtaining the tissue specimen until freezing was less than 30 seconds. Glutamate concentrations were measured using a 2300 STAT Plus analyzer (Yellow Springs Instrument Co., Yellow Springs, Ohio, USA). Statistical analysis. All data are expressed as mean \pm SE. Comparisons of values measured before and after $\mathrm{T}_{3}$ treatment were made using the paired Student's $t$ test.

\section{Results}

Three days of $T_{3}$ treatment induced a mild hyperthyroid state in these subjects, as reflected by a significant increase in plasma $T_{3}$ concentration that was associated with suppression of the mean concentration of thyroid stimulating hormone (TSH) in plasma, a 30\% increase in heart rate, a $17 \%$ increase in the mean rate of whole-body oxygen consumption (Table 1), and a $15 \%$ increase in whole-body energy expenditure (basal: $1819 \pm 129 \mathrm{kcal} / 24 \mathrm{~h}$ vs. $2089 \pm 141 \mathrm{kcal} / 24 \mathrm{~h}$ after $\mathrm{T}_{3}$ treatment; $P<0.02$ ) as assessed by indirect calorimetry.

The rate of ATP synthesis as assessed by ${ }^{31} \mathrm{P}$ NMR was $5.2 \pm 0.6 \mu \mathrm{mol} / \mathrm{g} / \mathrm{min}$ in the basal state and it did not change significantly after $\mathrm{T}_{3}$ treatment $(4.6 \pm 0.8$ $\mu \mathrm{mol} / \mathrm{g} / \mathrm{min} ; P=0.16 \mathrm{vs}$. basal), as shown in Figure 4 .

In contrast, the mean rate of the TCA cycle as assessed by ${ }^{13} \mathrm{C}$ NMR from the rate of ${ }^{13} \mathrm{C}$ incorporation into glutamate $\mathrm{C} 4$ and $\mathrm{C} 2$ increased by $70 \%$ after $\mathrm{T}_{3}$ treatment $(P=0.01 \mathrm{vs}$. basal). The TCA cycle flux was $0.064 \pm 0.008 \mu \mathrm{mol} / \mathrm{g} / \mathrm{min}$ in the basal state, and increased to $0.109 \pm 0.013 \mu \mathrm{mol} / \mathrm{g} / \mathrm{min}$ after $T_{3}$ administration (Figure 4).

An estimate of mitochondrial energy coupling was obtained by expressing the ratio of ATP synthesis to

Table 1

Effect of T3 treatment on clinical and metabolic parameters

\begin{tabular}{lcccccccc}
\hline Body weight & Heart rate & Thyroxine $\mathrm{T}_{4}$ & $\begin{array}{c}\text { Thyroid binding } \\
\text { capacity } \\
(\mu \mathrm{gg} / \mathrm{dl})\end{array}$ & $\begin{array}{c}\text { Estimated } \\
\text { free thyroxine } \\
(\mathrm{ng} / \mathrm{dl})\end{array}$ & $\mathrm{T}_{3}$ & $\begin{array}{c}\text { TSH } \\
(\mathrm{ng} / \mathrm{dl})\end{array}$ & $\begin{array}{c}\text { Whole-body } \\
(\mu \mathrm{U} / \mathrm{ml})\end{array}$ & $\begin{array}{c}\text { oxygen consumption } \\
(\mathrm{ml} / \mathrm{min})\end{array}$ \\
Basal & $67 \pm 4$ & $63 \pm 2$ & $7.1 \pm 0.4$ & $19.1 \pm 1.1$ & $1.77 \pm 0.09$ & $93 \pm 5$ & $1.66 \pm 0.35$ & $257 \pm 11$ \\
Post- $\mathrm{T}_{3}$ & $66 \pm 4$ & $82 \pm 5$ & $3.6 \pm 0.4$ & $17.8 \pm 1.0$ & $1.65 \pm 0.10$ & $552 \pm 30$ & $0.04 \pm 0.01$ & $295 \pm 12$ \\
& $P<0.05$ & $P<0.001$ & $P<0.0005$ & $P<0.005$ & $P=0.11$ & $P<0.0001$ & $P<0.01$ & $P=0.04$ \\
\hline
\end{tabular}

Body weight; heart rate; plasma thyroxine; thyroid binding capacity; estimated free thyroxine, $\mathrm{T}_{3}$, and TSH concentrations; and whole-body oxygen consumption measured by indirect calorimetry in the subjects before and after $\mathrm{T}_{3}$ treatment. 

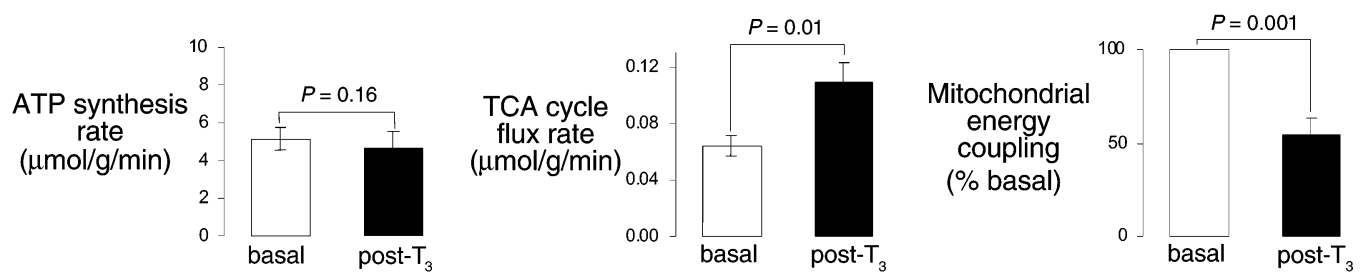

\section{Figure 4}

Muscle TCA cycle and ATP synthesis fluxes measured in seven volunteers before (basal) and after $\mathrm{T}_{3}$ treatment (post- $\mathrm{T}_{3}$ ). Thyroid hormone induces a significant increase in muscle TCA cycle flux, whereas the rate of ATP synthesis does not show any significant change. The resulting ATP/TCA ratio (normalized to the basal state) reflects a decrease in mitochondrial energy coupling following $T_{3}$ treatment.

TCA cycle flux, normalized to the basal state and this was found to decrease by $45 \%$ after $\mathrm{T}_{3}$ treatment $(P=0.001$ vs. basal) (Figure 4).

\section{Discussion}

While it is well established that thyroid hormone regulates metabolic rate in humans, the mechanism by which it does so remains unknown. Although $\mathrm{T}_{3}$ has been shown to increase energy needs by activating ion pumping across membranes (2), substrate cycling $(3,4)$, and protein synthesis (5), regulation of basal metabolic rate by uncoupling substrate oxidation from ATP synthesis has been postulated (6) but never before demonstrated in humans.

In order to address this question, we used a novel ${ }^{13} \mathrm{C} /{ }^{31} \mathrm{P} N M R$ approach to measure $\mathrm{T}_{3}$-induced changes in mitochondrial energy coupling in human skeletal muscle. We found that three days of $\mathrm{T}_{3}$ treatment increased skeletal muscle TCA cycle flux by $70 \%$ that was associated with no significant change in the rate of ATP synthesis. Since there was a disproportionate increase in TCA cycle flux compared with ATP synthesis, these results suggest that $T_{3}$ promotes increased thermogenesis in part by promoting mitochondrial energy uncoupling in skeletal muscle.

The TCA cycle is coupled to muscle oxygen consumption via a stoichiometric relationship with substrate utilization (24). Therefore it is likely that the 70\% $\mathrm{T}_{3}$-induced increase in TCA cycle flux reflects a similar increase in muscle oxygen consumption. In contrast, whole-body oxygen consumption increased by only $17 \%$ following $\mathrm{T}_{3}$ treatment. The difference in magnitude between the $T_{3}$-induced increase in muscle versus wholebody oxygen consumption can probably be ascribed to the limited contribution of resting skeletal muscle to whole-body oxygen consumption (25), and demonstrates the important advantage of this tissue-specific NMR method over whole-body indirect calorimetry. Furthermore, if one extrapolates the observed $\mathrm{T}_{3}$-induced increase in muscle energy metabolism to the whole body, it can be estimated to account for an increase of approximately $7 \%$ in whole-body oxygen consumption. The remainder $(\sim 10 \%)$ can most likely be explained by the contribution of other tissues such as liver, kidney, and heart to whole-body oxygen consumption (26).

Uncoupling effects of high doses of thyroid hormone have previously been reported in vitro $(6,7)$, and more recently $T_{3}$-induced proton leaks in the inner mitochondrial membrane have been demonstrated in vitro in rat liver (27) and rat skeletal muscle $(28,29)$. However, no evidence of a similar uncoupling effect in humans has yet been demonstrated, due to the difficulty in extrapolating in vitro measurements of isolated mitochondrial membrane permeability to the in vivo situation. Another difficulty in extrapolating the in vitro data to in vivo conditions is that the in vitro measurements are usually performed on isolated mitochondria under nonlimiting concentrations of ADP (state 3 respiration), in which proton leaks play a minor role (30). Under in vivo basal conditions, skeletal muscle respiration is likely to be operating under conditions of limited ADP (state 4 respiration), where proton leaks may account for a more important fraction of oxygen consumption $(6,31)$. The in vivo NMR method used in this study circumvents these limitations by assessing mitochondrial energy coupling in intact skeletal muscle under ambient ADP concentrations.

The mechanism by which thyroid hormone might promote increased mitochondrial uncoupling is unknown. However, a skeletal muscle-specific uncoupling protein (UCP-3) has recently been cloned in humans, and has been shown to be unregulated by thyroid hormone (9-18). This protein is thought to create a pathway that allows exothermic movement of protons through the inner mitochondrial membrane, and it has been speculated that UCP-3 might be involved in regulating energy expenditure and body weight in humans. Whether UCP-3 mediates mitochondrial uncoupling or not remains unclear. It has been reported recently that UCP-3 null mice have a normal response to thyroid hormone (32). On the other hand, transgenic mice with UPC-3 overexpression in skeletal muscle are hyperphagic and lean (33). However, the very high level of UCP-3 overexpression reported in these mice ( $\sim 60$-fold) does not argue in favor of UCP-3 being an efficient mitochondrial uncoupler. Taken together, these data suggest that an increase in UCP-3 expression may not be the only factor responsible for the observed $\mathrm{T}_{3}$-induced increase in mitochondrial uncoupling.

Given the increasing prevalence of obesity in the industrialized nations (34), there is considerable interest in the regulation of uncoupling protein expression and activity as a means of promoting nonshivering thermogenesis and weight loss. Although thyroid hormone 
promotes UCP-3 expression, the ubiquitous distribution of thyroid hormone receptor and action throughout the body, especially in the heart and central nervous system, limits its use in this regard. In contrast, UCP-3 is expressed almost exclusively in skeletal muscle, and the present data would support UCP-3 as a possible pharmacological target to promote weight loss through selective increases in mitochondrial energy uncoupling in this tissue. Furthermore, conversion of intramyocellular lipid into heat by this mechanism would also be predicted to reverse fat-induced insulin resistance (35).

In summary, we used a novel NMR approach to measure $T_{3}$-induced changes in mitochondrial energy coupling in human skeletal muscle. We found that three days of $\mathrm{T}_{3}$ treatment induced a disproportionate increase in TCA cycle flux compared with ATP synthesis in skeletal muscle. These data demonstrate that $\mathrm{T}_{3}$ can increase thermogenesis in skeletal muscle by promotion of mitochondrial uncoupling that may be partly mediated by an increase in UCP-3 protein expression. This in vivo NMR approach should be useful for exploring the roles of mitochondrial energy uncoupling processes in regulating energy metabolism and obesity in humans.

\section{Acknowledgments}

The authors would like to thank Joan Boyer, Laura Burden, Damien Nuzzo, and the staff of the Yale-New Haven Hospital General Clinical Research Center for expert technical assistance, Terry Nixon for maintenance and upgrades to the spectrometer, Peter Brown for coil construction, Jun Shen for assistance in pulse sequence implementation, Graeme Mason for assistance in modeling, and Gerard Burrow for helpful discussions. This work was supported by grants from the United States Public Health Service (R01 DK-49230, P30 DK-45735, and M01 RR-00125) and a K-23 award to K.F. Petersen. V. Lebon and S. Dufour are research associates and G.I. Shulman is an investigator of the Howard Hughes Medical Institute.

1. Magnus-Levi, A. 1895. Uber den respiratorischen Gaswechsel unter dem Einfluss des Thyroidea sowie unter vershiedenen pathalogishen Zustanden. Berl. Klin. Wochenschr. 34:650.

2. Izmail-Beigi, F., and Edelman, I.S. 1970. Mechanism of thyroid calorigenesis: role of active sodium transport. Proc. Natl. Acad. Sci. USA. 67:1071-1078

3. Newsholme, E.A., and Crabtree, B. 1976. Substrate cycles in metabolic regulation and in heat generation. Biochem. Soc. Symp. 41:61-109.

4. Shulman, G.I., Ladenson, P.W., Wolfe, M.H., Ridgway, E.C., and Wolfe, R.R. 1985. Substrate cycling between gluconeogenesis and glycolysis in euthyroid, hypothyroid, and hyperthyroid man. J. Clin. Invest. 76:757-764.

5. Gustafsson, R., Tata, J.R., Lindberg, O., and Ernster, L. 1965. The relationship between the structure and activity of rat skeletal muscle mitochondria after thyroidectomy and thyroid hormone treatment. J. Cell. Biol. 26:555-578.

6. Freake, H.C., and Oppenheimer, J.H. 1995. Thermogenesis and thyroid function. Annu. Rev. Nutr. 15:263-291.

7. Lardy, H.A., and Feldcott, G. 1951. Metabolic effects of thyroxine in vitro. Ann. NY Acad. Sci. 54:636-648.

8. Martius, C., and Hess, B. 1951. The mode of action of thyroxin. Arch. Biochem. Biophys. 33:486-487.

9. Boss, O., et al. 1997. Uncoupling protein-3: a new member of the mito- chondrial carrier family with tissue-specific expression. FEBS Letters. 408:39-42.

10. Gong, D.W., He, Y., Karas, M., and Reitman, M. 1997. Uncoupling protein-3 is a mediator of thermogenesis regulated by thyroid hormone, $\beta 3$ adrenergic agonists, and leptin. J. Biol. Chem. 272:24129-24132.

11. Jekabsons, M.B., Gregoire, F.M., Schonfeld-Warden, N.A., Warden, C.H., and Horwitz, B.A. 1999. $T_{3}$ stimulates resting metabolism and UCP-2 and UCP-3 mRNA but not nonphosphorylating mitochondrial respiration in mice. Am. J. Physiol. 277:E380-E389.

12. Jucker, B.M., et al. 2000. Assessment of mitochondrial energy coupling in vivo using a novel ${ }^{13} \mathrm{C} /{ }^{31} \mathrm{P}$ NMR approach. Proc. Natl. Acad. Sci. USA. 97:6880-6884.

13. Masaki, T., Yoshimatsu, H., and Sakata, T. 2000. Expression of rat uncoupling protein family mRNA levels by chronic treatment with thyroid hormone. Int. J. Obes. Relat. Metab. Disord. 24(Suppl. 2):S162-S164.

14. Cusin, I., Rouru, J., Visser, T., Burger, A.G., and Rohner-Jeanrenaud, F. 2000 Involvement of thyroid hormones in the effect of intracerebroventricular leptin infusion on uncoupling protein-3 expression in rat muscle. Diabetes. 49:1101-1105.

15. Larkin, S., et al. 1997. Regulation of the third member of the uncoupling protein family, UCP3, by cold and thyroid hormone. Biochem. Biophys. Res. Commun. 240:222-227.

16. Gong, D.W., He, Y., Karas, M., and Reitman, M. 1997. Uncoupling protein-3 is a mediator of thermogenesis regulated by thyroid hormone, B3adrenergic agonists, and leptin. J. Biol. Chem. 272:24129-24132.

17. Pedersen, S.B., et al. 1999. Regulation of uncoupling protein-2 and -3 by growth hormone in skeletal muscle and adipose tissue in growth hormone-deficient adults. J. Clin. Endocrinol. Metab. 84:4073-4078.

18. Barbe, P., et al. 2001. Triidothyronine-mediated upregulation of UCP2 and UCP3 mRNA expression in human skeletal muscle without coordinated induction of mitochondrial chain genes. FASEB J. 15:13-15.

19. Harris, R.C., Hultman, E., and Nordesjo, L.O. 1974. Glycogen, glycolytic intermediates and high energy phosphates determined in biopsy samples of musculus quadriceps femoris of man at rest. Scand. J. Clin. Lab. Invest. 33:109-120.

20. Shen, J., Rycyna, R.E., and Rothman, D.L. 1997. Improvements on an in vivo automatic shimming method (FASTERMAP). Magn. Reson. Med. 38:834-839.

21. Mason, G.F., Rothman, D.L., Behar, K.L., and Shulman, R.G. 1992. NMR determination of the TCA cycle rate and alpha-ketoglutarate/glutamate exchange rate in rat brain. J. Cereb. Blood Flow Metab. 12:434-447.

22. Mason, G.F. 2000. CWave: software for the design and analysis of ${ }^{13} \mathrm{C}$ labeling studies performed in vivo. Proc. Intl. Soc. Mag. Reson. Med. 3:1870 (Abstr.)

23. Chatham, J.C., Forder, J.R., Glickson, J.D., and Chance, E.M. 1995. Calculation of absolute metabolic flux and the elucidation of the pathways of glutamate labeling in perfused rat heart by 13C NMR spectroscopy and nonlinear least squares analysis. J. Biol. Chem. 270:7999-8008.

24. Stryer, L. 1995. Biochemistry. W.H. Freeman and Company. New York, New York, USA. 507-558.

25. Field, J., Beldings, H.S., and Martin, A.W. 1939. An analysis of the relation between basal metabolism and summated tissue respiration in the rat. Journal of Cellular and Comparative Physiology. 14:143-157.

26. Barker, S.B., and Klitgaard, H.M. 1952. Metabolism of tissues excised from thyroxine-injected rats. Am. J. Physiol. 170:81-86.

27. Brand, M.D., Steverding, D., Kadenbach, B., Stevenson, P.M., and Hafner, R.P. 1992. The mechanism of the increase in mitochondrial proton permeability induced by thyroid hormones. Eur. J. Biochem. 15:775-781.

28. Porter, R.K., et al. 1999. Indirect measurement of mitochondrial proton leak and its application. Int. J. Obes. Relat. Metab. Disord. 23:S12-S18.

29. Lanni, A., et al. 1999. Expression of uncoupling protein-3 and mitochondrial activity in the transition from hypothyroid to hyperthyroid state in rat skeletal muscle. FEBS Lett. 444:250-254.

30. Groen, A.K., Wanders, R.J., Westerhoff, H.V., Van der Meer, R., and Tager, J.M. 1982. Quantification of the contribution of various steps to the control of mitochondrial respiration. J. Biol. Chem. 25:2754-2757.

31. Hafner, R.P., Nobes, C.D., McGown, A.D., and Brand, M.D. 1988. Altered relationship between protonmotive force and respiration rate in nonphosphorylating liver mitochondria isolated from rats of different thyroid hormone status. Eur. J. Biochem. 15:511-518.

32. Gong, D.W., et al. 2000. Lack of obesity and normal response to fasting and thyroid hormone in mice lacking uncoupling protein-3. J. Biol. Chem. 275:16251-16257.

33. Clapham, J.C., et al. 2000. Mice overexpressing human uncoupling protein-3 in skeletal muscle are hyperphagic and lean. Nature. 406:415-418.

34. Flegal, K.M., Carroll, M.D., Kiczmarski, R.J., and Johnson, C.L. 1998. Overweight and obesity in the United States: prevalance and trends, 1960-1994. Int. J. Obes. Relat. Metab. Disord. 22:39-47.

35. Shulman, G.I. 2000. Cellular mechanisms of insulin resistance. J. Clin. Invest. 106:171-176. 